\title{
Species distribution modelling of marine benthos: a North Sea case study
}

\author{
Henning Reiss ${ }^{1,3, *}$, Sarah Cunze ${ }^{2}$, Konstantin König ${ }^{2,4}$, Hermann Neumann $^{1,2}$, \\ Ingrid Kröncke ${ }^{1}$
}

\begin{abstract}
${ }^{1}$ Senckenberg Institute, Department for Marine Research, Südstrand 40, 26382 Wilhelmshaven, Germany ${ }^{2}$ Biodiversity and Climate Research Centre Frankfurt (BiK-F), Senckenberganlage 25, 60325 Frankfurt am Main, Germany ${ }^{3}$ University of Nordland, Faculty of Biosciences and Aquaculture, Postbox 1490, 8049 Bodø, Norway

${ }^{4}$ World Agroforestry Center - ICRAF Travessa Dr. Eneas Pinheiro s/n Embrapa Amazonia Oriental, 66095-100 Belem (PA), Brazil
\end{abstract}

\begin{abstract}
Species distribution models (SDMs) were applied to predict the distribution of benthic species in the North Sea. An understanding of species distribution patterns is essential to gain insight into ecological processes in marine ecosystems and to guide ecosystem management strategies. Therefore, we compared 9 different SDM methods, including GLM, GBM, FDA, SVM, RF, MAXENT, BIOCLIM, GARP and MARS, by using 10 environmental variables to model the distribution of 20 marine benthic species. Most of the models showed good or very good performance in terms of predictive power and accuracy, with highest mean area under the curve (AUC) values of 0.845 and 0.840 , obtained for the MAXENT and GBM models, respectively. The poorest performance was shown by the BIOCLIM model, which had a mean AUC of 0.708 . Nevertheless, the mapped distribution patterns varied remarkably depending on the model used, with up to $32.5 \%$ differences in predictions between models. For species with a narrow distribution range, the models showed a better performance based on the AUC than for species with a broad distribution range, which can most likely be attributed to the restricted spatial scale and the model evaluation procedure. Of the environmental variables, bottom water temperature and depth had the greatest effect on the distribution of 14 benthic species, based on MAXENT results. We examine the potential utility of this strategy for predicting future distribution of benthic species in response to climate change.
\end{abstract}

KEY WORDS: Habitat suitability modelling $\cdot$ Niche modelling $\cdot$ Marine ecosystems $\cdot$ Macrofauna Benthic communities $\cdot$ North Sea Resale or republication not permitted without written consent of the publisher

\section{INTRODUCTION}

Knowledge of the spatial distribution of species and communities in ecosystems is an essential prerequisite for the understanding of ecosystem functioning and processes as well as conservation and spatial planning issues. Especially in the marine environment, where fauna is more difficult to access and monitor than in terrestrial systems, these requirements are often addressed with fragmentary information about the species and habitats. Therefore, predictive methods became important to overcome these problems (Guisan \& Zimmermann 2000, Guisan \&
Thuiller 2005). Species distribution models (SDMs), also known as habitat suitability models, ecological niche models or bioclimatic envelopes, are correlative approaches that use full spatial coverage data of environmental variables to explain patterns of species distribution (Elith \& Graham 2009). Terrestrial ecology uses these statistical and machine-learning methods to predict species distribution not only for conservation and management purposes, but also for forecasting the effects of environmental or climate change (Guisan \& Thuiller 2005, Heikkinen et al. 2006, Pompe et al. 2008, Elith \& Leathwick 2009, Kharouba et al. 2009). 
The application of SDMs in the marine environment is recent (Robinson et al. 2011), stimulated by increasing availability of large-scale environmental data, better understanding of the relationship between environmental variables and species distribution, and the need for prognostic tools to predict changes in species distribution in response to environmental or climatic changes (Degraer et al. 2008, Glockzin et al. 2009, Gogina et al. 2010). Given the need for ecosystem-based fisheries management, most recent studies using SDMs in marine ecosystems have focussed on the distribution of commercial fish species (Venables \& Dichmont 2004, Maxwell et al. 2009, Moore et al. 2010, Lenoir et al. 2011). In contrast, few studies have applied SDMs to the distribution of marine invertebrate benthos. Ysebaert et al. (2002) used logistic regression to model benthic species distribution in the Westerschelde estuary in the Netherlands, and Thrush et al. (2003) and Ellis et al. (2006) modelled the distribution of macrobenthic species in New Zealand estuaries with a similar approach. In the North Sea, most studies applying SDMs were carried out on a local scale, such as polychaete distribution in the German Bight using multivariate adaptive regression splines (MARS; Meißner et al. 2008), as well as community type and polychaete distribution in Belgium waters using discriminant function analysis, and artificial neural networks plus generalized linear models (GLMs), respectively (Degraer et al. 2008, Willems et al. 2008). Gogina et al. (2010) and Gogina \& Zettler (2010) also modelled macrobenthic patterns in the Baltic Sea using GLMs.

The North Sea is one of the most intensively exploited and studied marine ecosystems in the world. The shelf sea area is characterised by high (seasonal) fluctuations of environmental variables in the shallower southern parts and less variable conditions in deeper waters towards the north. The increasing anthropogenic pressures on the entire North Sea, such as commercial fisheries, aquaculture, wind farms and transport routes, result in an urgent need for effective spatial marine planning and management to minimise adverse effects on the ecosystem. The benthic fauna is an important ecosystem component, playing a vital role in nutrient cycling and detrital decomposition. As a food source for higher trophic levels and a consumer of primary producers and other first order consumers, it is affected by bottomup and top-down processes. Intensive studies in the last decades on the importance of different environmental factors in structuring benthic communities and species distribution in the North Sea show that food availability, sediment structure, and hydrody- namic regime influence distribution on various spatial scales (e.g. Callaway et al. 2002, Wieking \& Kröncke 2003, Reiss et al. 2010). Nevertheless, full coverage predictions of species and community distribution for the entire North Sea area are lacking.

Therefore, the objectives of this study are (1) to apply and compare several species distribution modelling methods on marine benthos and (2) to predict the distribution of selected characteristic and dominant macrobenthic species of the North Sea. This is the first study of modelling benthic species distribution for the entire North Sea area.

\section{MATERIALS AND METHODS}

\section{Benthic data}

The benthic species data were extracted from the benthic data sets of the ICES North Sea Benthos Project 2000 (NSBP 2000) and the EU Project Managing Fisheries to Conserve Groundfish and Benthic Invertebrate Species Diversity (MAFCONS). Only infaunal samples with grabs or corers were used in this study, representing 1820 stations for the entire North Sea area for the period 2000 to 2004. Details of sampling and sample processing are given by Rees et al. (2007) and Callaway et al. (2007). Based on previous studies of North Sea benthic communities (e.g. Rees et al. 2007, Reiss et al. 2010, Kröncke et al. 2011), we selected 20 characteristic or dominant benthic species that represented rare species as well as widely and narrowly distributed species.

\section{Environmental data}

A set of environmental data were selected and further resampled by bilinear interpolation to a resolution of 0.6 arc-minutes with ArcGIS 9.3 (ESRI), R (R Development Core Team 2009) and ERDAS Imagine 9.1 (ERDAS).

Sediment data were collected during the sampling campaigns of the NSBP 2000 and the MAFCONS projects. As sampling processing was not standardised for NSBP 2000, the datasets for which fractional data were available were reprocessed to yield uniformly calculated means, sorting coefficients and descriptive assessments, which we then analysed in GRADISTAT, Version 4.0 (Blott \& Pye 2001). The granulometry of the MAFCONS samples was determined with a Laser Particle Sizer ('Analysette 22 Economy', Fritsch) for mud content and median grain size (for 
details see Callaway et al. 2007). All sediment data were compiled and interpolated to the entire area by inverse distance weighting.

Depth data were derived from the General Bathymetric Charts of the Oceans (GEBCO) global bathymetry data set from the British Oceanographic Data Centre with a spatial resolution of a 1 arc-minute grid (GEBCO 2003).

Data on temperature, salinity and primary production were provided by the Institute of Oceanography (Hamburg, Germany). Bottom temperature and salinity were derived from the hydrodynamic Hamburg Shelf Ocean Model (HAMSOM), a 3-dimensional, baroclinic primitive equation model for simulations of oceanic and coastal and shelf sea dynamics (Backhaus 1985). The model's horizontal resolution is 12 ' of latitude and $20^{\prime}$ of longitude with a maximum vertical resolution of 19 layers. For details on the specific HAMSOM application see Pohlmann (1996). Instead of using annual mean values, data from the months of February and June 2000 were used for the distribution modelling to reflect the general seasonal patterns of temperature and salinity in the North Sea.

Annual primary production data of the water column for the year 2000 were based on the ECOlogical North Sea Model HAMburg (ECOHAM1). The ECOHAM1 model can calculate annual and long-term phytoplankton dynamics, nutrient transport and primary productivity for shelf seas in a 3-dimensional physical environment (Skogen \& Moll 2005). The horizontal grid size of the numerical model is $20 \times 20 \mathrm{~km}$ and the vertical resolution is $5 \mathrm{~m}$ for the upper $50 \mathrm{~m}$ with increasing layer thickness below $50 \mathrm{~m}$ up to a maximum of 19 layers. The ECOHAM1 model was validated using observed chlorophyll (Moll 1998), phosphate concentrations (Moll 2000) and primary production values (Skogen \& Moll 2000).

Chlorophyll a pigment concentrations were provided by the Marine and Coastal Information Services (MarCoast) project, based on remote sensing images derived from the Medium Resolution Imaging Spectrometer (MERIS). The concentration of chlorophyll a was derived from the sea surface between 2 to $15 \mathrm{~m}$ water depth, depending on the turbidity of the water (for details see ESA 2006). Mean values for the period February to April 2008 and 2009 were used in this study to cover the spatial extent of the characteristic spring phytoplankton bloom in this region.

Data on peak wave stress and stratification were provided by the Proudman Oceanographic Laboratory (Liverpool, UK) and generated using a 3-dimensional hydrodynamic model (Davies \& Aldridge
1993). Peak wave stress was calculated from a $1 \mathrm{yr}$ model run covering the period September 1999 to September 2000, on an approximately $12 \mathrm{~km}$ grid, using the Wave Analysis Model spectral wave model run at the Proudman Oceanographic Laboratory (Osuna \& Wolf 2005). The stratification parameter ' $\mathrm{S}$ ' was derived from the formulation presented by Pingree \& Griffiths (1978), using modelled M2 tidal velocities and measured depths.

\section{SDMs}

The different models were trained using the Maxent v3.3.3a software for the maximum entropy model (MAXENT) (Phillips et al. 2006), the R environment software with the BIOMOD package 1.1-5 for GLMs, generalised boosting models (GBM), MARS, random forests (RF) and mixture discriminant analysis $(\mathrm{MDA}=\mathrm{FDA})$ (Thuiller 2003, R Development Core Team 2009), and the openModeller 1.0.9 framework for the Bioclimatic Envelope (BIOCLIM), the genetic algorithm for rule-set prediction (GARP) and the Support Vector Machines (SVM) (Muñoz et al. 2011). The models were trained using 1000 and 10000 pseudoabsence points in BIOMOD/openModeller and MAXENT, respectively.

MAXENT. MAXENT estimates a target probability distribution by finding the probability distribution of maximum entropy (i.e. that is most spread out, or closest to uniform) and constraining the expected value of each environmental variable to match its empirical average (Phillips et al. 2006). For presenceonly species distribution modelling, MAXENT fits an unknown probability distribution within the environmental space defined by the input variable to the pixel values of known species occurrence records. The unknown probability distribution is proportional to the probability of occurrence (Elith et al. 2006, 2011).

GLM. GLMs are regression-type models closely related to the statistical methods used in linear modelling and analysis of variance. GLM not only uses linear relationships between response and predictor variables, it also uses parametric functions such as a combination of linear, quadratic or cubic terms. An automatic stepwise procedure generates the best model by minimizing the Akaike information criterion (AIC). This stepwise procedure removes redundancy in variables and reduces multicollinearity (Thuiller 2003, Thuiller et al. 2009).

GBM. GBM fits a large number of 'simple' models and combines the prediction to generate a robust 
response estimate. In GBM, each individual model consists of classification or regression trees, also called boosted regression trees (BRT). In an iterative process a final model develops by progressively adding trees, while re-weighting the data poorly predicted by the previous tree (for more details see Ridgeway 2007, Elith et al. 2008). Prior to modelling, we defined 3000 trees as a basis for fitting.

MARS. Compared to other methods based on linear relationships, where the coefficients remain constant across different levels of environmental variables, the MARS approach identifies and estimates a model whose coefficients differ depending on the level of the predictor variable. It combines linear regression, mathematical construction of splines and binary recursive partitioning to model linear or nonlinear relationships between environmental variables and species occurrence (Friedman 1991).

RF. RF is a classification and regression model that generates multiple classification trees with a randomised subset of predictors. The number of predictors used for the best split at each tree branch is a random subset of predictors, and trees are aggregated by averaging (Prasad et al. 2006). In this study we used 500 trees.

BIOCLIM. BIOCLIM is an envelope model that uses mean and standard deviation for each environmental variable to calculate bioclimatic envelopes (Busby 1986, Nix 1986). Only species presence data are required. Points are classified as suitable if all associated environmental values fall within the calculated envelopes, marginal if one or more associated environmental value falls outside the calculated envelope, but still within the upper and lower limits, and unsuitable if one or more associated environmental value falls outside the upper and lower limits. The categorical output of BIOCLIM is given as probabilities of 1.0, 0.5 and 0.0, respectively.

GARP. GARP is a machine-learning approach using a genetic algorithm to select a set of rules (e.g. logistic regression, bioclimatic rules) that best predict the species distribution (Stockwell \& Peters 1999). We have applied the 'best subset' procedure implemented in openModeller, which selects the best models based on omission and commission error statistics (Peterson et al. 2007). A general description and technical details of the GARP modelling approach have been provided by Stockwell \& Peters (1999).

SVM. SVM is a machine-learning method that belongs to a family of generalised linear classifiers. To estimate the potential distribution of a species subject to the environmental conditions, the eco-space (spanned by the environmental variables) is separated by a hyperplane into 2 target classes (Guo et al. 2005): suitable and unsuitable environmental conditions. The optimality criterion used to find the separating hyperplane is maximised distance to the (nearest) training data points (large margin separation). With the help of a kernel function, the data points (representing known presence and absence records in the ecospace) can be mapped in a higher dimensional space in which complicated patterns can be more simply represented (Drake et al. 2006).

FDA. FDA is an extension of linear discriminant analysis. Linear discriminant analysis assumes that the distribution of each class (presence and absence) follows a Gaussian distribution. This restriction is extended in FDA by allowing a mixture of Gaussian distributions (Marmion et al. 2009).

\section{Evaluation measures}

In general, model accuracy was evaluated by datasplitting using $70 \%$ of the data to train the model and the remaining $30 \%$ to test the performance. The results were evaluated by using the area under the receiver operating characteristic curve (AUC) and Cohen's kappa ( $\kappa)$ as evaluation measures. Both measures were calculated by using the ROC-AUC v 1.3 software (Schröder 2006). The AUC is a thresholdindependent measure representing the relationship between sensitivity and the corresponding proportion of false positives (1-specificity). The AUC varies between 0 and 1 , with values above 0.9 indicating excellent prediction, between 0.7 and 0.9 indicating good prediction, below 0.7 indicating poor predictions, and below 0.5 indicating a prediction no better than random (Hosmer \& Lemeshow 2000). For the AUC calculation we used 10000 randomly chosen pseudo-absence points. We tested AUC values for significant differences to a critical AUC of 0.7 following the method of Beck \& Shultz (1986). The AUC is considered a highly effective measure for the performance of SDMs, because it does not require a specific threshold and is independent from prevalence (the proportion of sites in which the species was predicted as present) (McPherson et al. 2004).

Cohen's kappa is another commonly used evaluation measure in ecological SDM studies with presence-absence data and is often applied when a specific threshold level is required. Kappa is based on a confusion matrix with a threshold at which $\kappa$ is maximised (Fielding \& Bell 1997). It ranges from -1 to 1 , with $\kappa$ values below 0 indicating a prediction no 
better than random (Cohen 1960). Values above 0.75 indicate excellent prediction, between 0.4 and 0.75 indicate good prediction and below 0.4 indicate poor predictions (Landis \& Koch 1977). In contrast to the AUC, $\kappa$ is dependent on prevalence (McPherson et al. 2004). For the calculation of $\kappa$, we randomly generated pseudo-absence data in a 1:1 ratio with the number of presence records.

We identified collinearity among the environmental parameters, using Pearson's correlation with $\mathrm{r}>$ 0.7 as a threshold level for collinearity (Booth et al. 1994). Only summer and winter salinity were highly correlated $(r=0.905)$, thus we omitted winter salinity prior to further analyses and modelling.

For further evaluation of the model predictions, we performed pairwise comparison of the output of any 2 models. For each model and species, we determined the number of grid cells for which the predicted occurrence was likely as well as unlikely. The probability that maximised $\kappa$ was used as a threshold for each model and species. We then calculated the percentage of the area with differences in the predictions. Thus, the percentage of area disagreement gives the proportion of the area where the probability of occurrence of one model is above its threshold value whereas the probability of the compared model is below its threshold. We calculated the mean percentage across all species for each pair of models.

The relative contribution of the environmental variables was quantified exemptively for the MAXENT model by using a jackknife cross-evaluation procedure. Here the model is calculated with 1 environmental variable and then without that variable but with all remaining variables. This procedure therefore quantifies the explanatory information in each variable when used in isolation and determines the individual effect of each environmental variable (Phillips 2005).

\section{RESULTS}

The 20 benthic species used for the application and comparison of the different SDMs were chosen inter alia because of their differences in geographical distribution patterns and widespread occurrence. Nonetheless, AUC values, as one measure of model performance, significantly exceeded the threshold of 0.7 indicating good or very good performances for most species and models (Table 1). Only the GARP and BIOCLIM models produced results that were not significantly above an AUC value of 0.7 for more

Table 1. Area under the receiver operating characteristic curve (AUC) values of the 20 benthic species for the different species distribution model (SDM) methods with number of occurrence points $(\mathrm{N})$. AUC values significantly above 0.7 are indicated by ${ }^{* * *} \mathrm{p}<0.0001$, ${ }^{* *} \mathrm{p}<0.01,{ }^{*} \mathrm{p}<0.05$

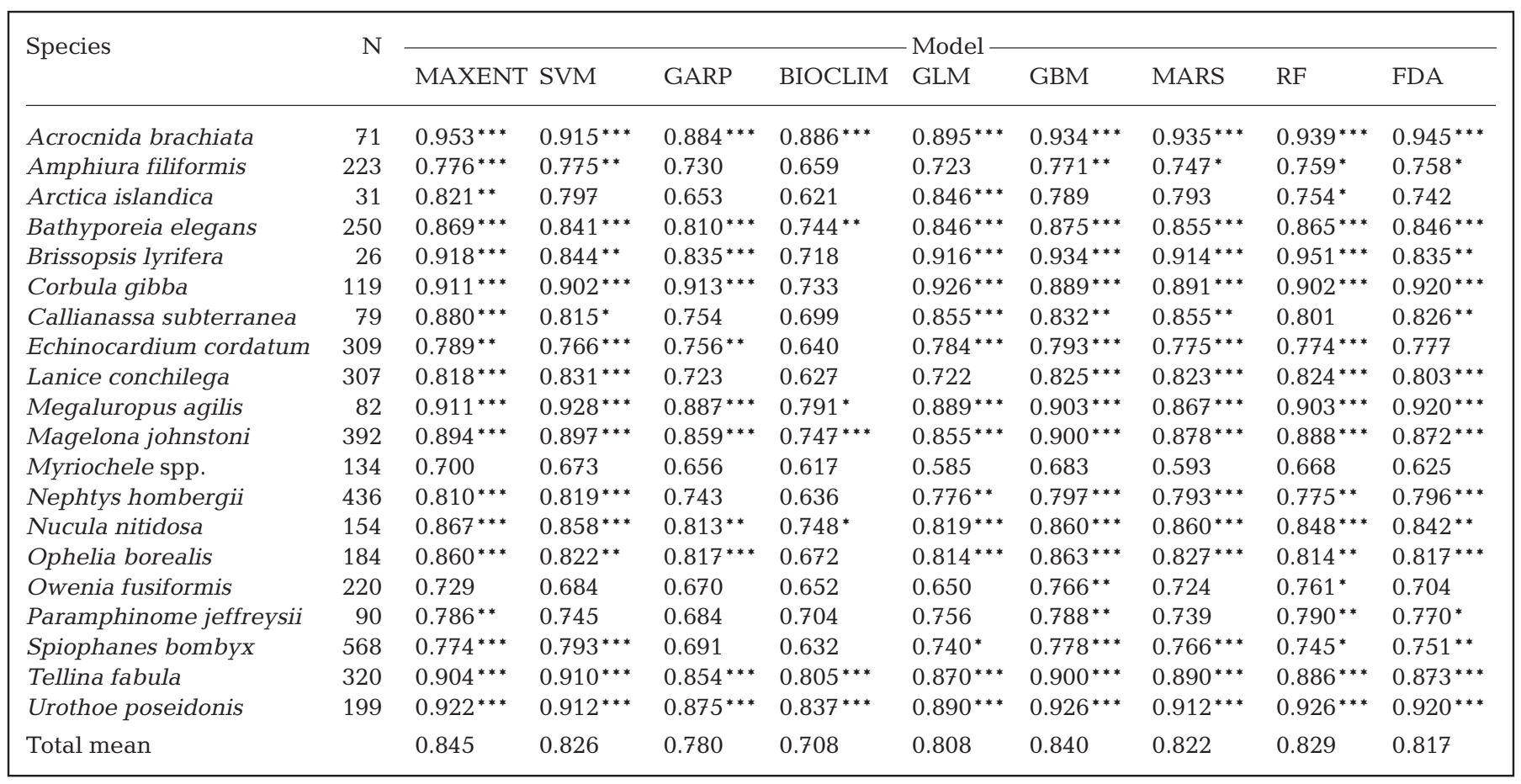


than 5 species (GARP: 9 species; BIOCLIM: 13 species), whereas the other models revealed fewer nonsignificant results (Table 1).

Fig. 1 shows mean AUC plotted against mean $\kappa$ for all models, reflecting a linear gradient in model performance. In general, BIOCLIM performed poorly with the lowest AUC value of $0.708 \pm 0.076$ (mean \pm SD), followed by GARP and GLM with intermediate performance and AUC values of $0.780 \pm 0.081$ and $0.808 \pm 0.088$, respectively (Fig. 1, Table 1). All other models clustered together in the upper part of the graph indicating similar good performance, with the best performance for GBM and MAXENT. For the latter models, the mean AUC value was $0.840 \pm 0.068$ and $0.845 \pm 0.068$, respectively (Table 1 ).

In general, the lowest AUC values were obtained for species widely distributed across the North Sea area, such as the polychaetes Owenia fusiformis, Spiophanes bombyx, Nephtys hombergii and Myriochele spp., and the echinoderms Amphiura filiformis and Echinocardium cordatum. In contrast, the highest AUC values were obtained for species with distributions restricted to a specific area of the North Sea, such as the echinoderm Acrocnida brachiata, the amphipod Urothoe poseidonis and the bivalves Corbula gibba and Tellina fabula (Table 1).

Despite the overall high AUC and $\kappa$ values, the maps from the different models showed remarkable differences in predicted distribution patterns. Fig. 2 shows the predictive maps of 4 selected species with contrasting distribution patterns, i.e. Acrocnida brachiata with a narrow southern distribution in the

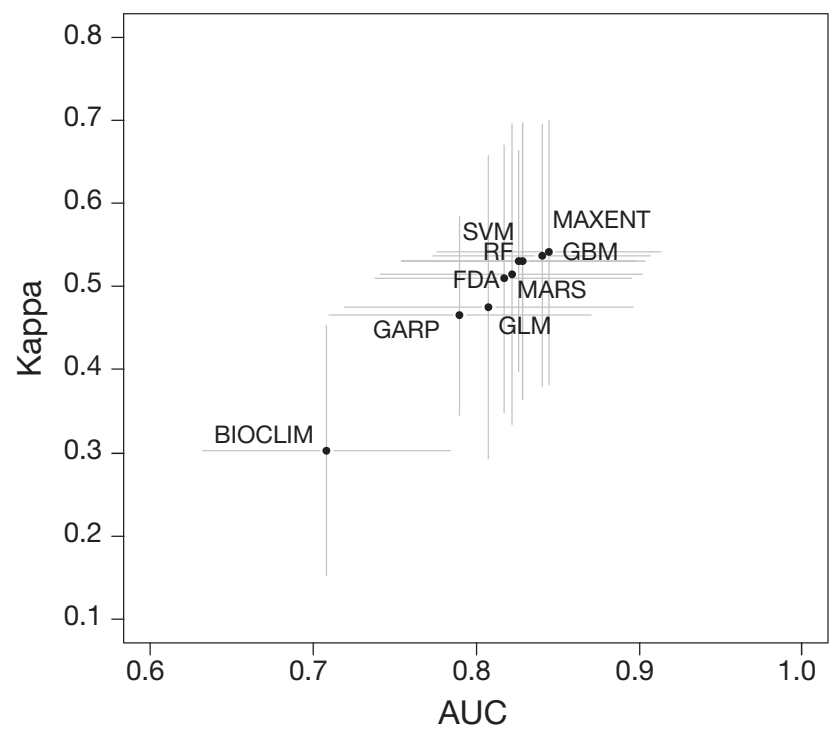

Fig. 1. Mean $( \pm \mathrm{SD})$ area under the receiver operating characteristic curve (AUC) versus mean Cohen's $\kappa$
North Sea, Amphiura filiformis with a wide distribution, Paramphinome jeffreysii with a northern distribution and the rare species Arctica islandica. Although the models produced different predictions for the potential distribution patterns to some extent, most models ascertained core distribution areas. For example, all models indicated the main distribution area of Acrocnida brachiata as the German Bight (southeastern North Sea) and the Dogger Bank (southern central North Sea), and the unsuitability of the northern North Sea (Fig. 2).

The largest differences in the percentage of area disagreement was found between BIOCLIM and any of the other models tested, with more than $28 \%$ differences in predictions in most cases (Table 2). The lowest percentage of area disagreement was between GBM and MAXENT (8.4\%), GBM and SVM $(12.1 \%)$, and MAXENT and SVM (12.2\%) (Table 2). These models predicted similar patterns as confirmed by visual comparison of predictive maps (Fig. 2). As with model performance, the highest disagreement was for species with a wide distribution range compared to geographically restricted species (results not shown).

The MAXENT model quantified the relative contribution of the environmental variables quite well (for predictive maps see Fig. 3). For 14 species, depth and bottom water temperature (summer and winter) were the most important determinants of distribution (Fig. 4). Species response to depth peaked mainly between 20 and $50 \mathrm{~m}$ for species with a southern distribution, which are consequently more broadly distributed than species in the deeper northern parts of the North Sea (Fig. 5). In contrast, summer bottom water temperature response showed more gradual progression (Fig. 5).

\section{DISCUSSION}

Few previous studies have modelled distributions of marine species, although the information is highly relevant for understanding marine benthic systems, for their protection, and for predicting future changes in marine ecosystems (Leathwick et al. 2008, Elith \& Leathwick 2009). Thus, the objectives of this study were to apply and compare multiple species distribution modelling methods by generating distribution predictions for 20 characteristic North Sea benthic species.

The results of our comparison of the different modelling approaches parallel recent extensive comparisons for terrestrial systems (Elith et al. 2006, Mey- 

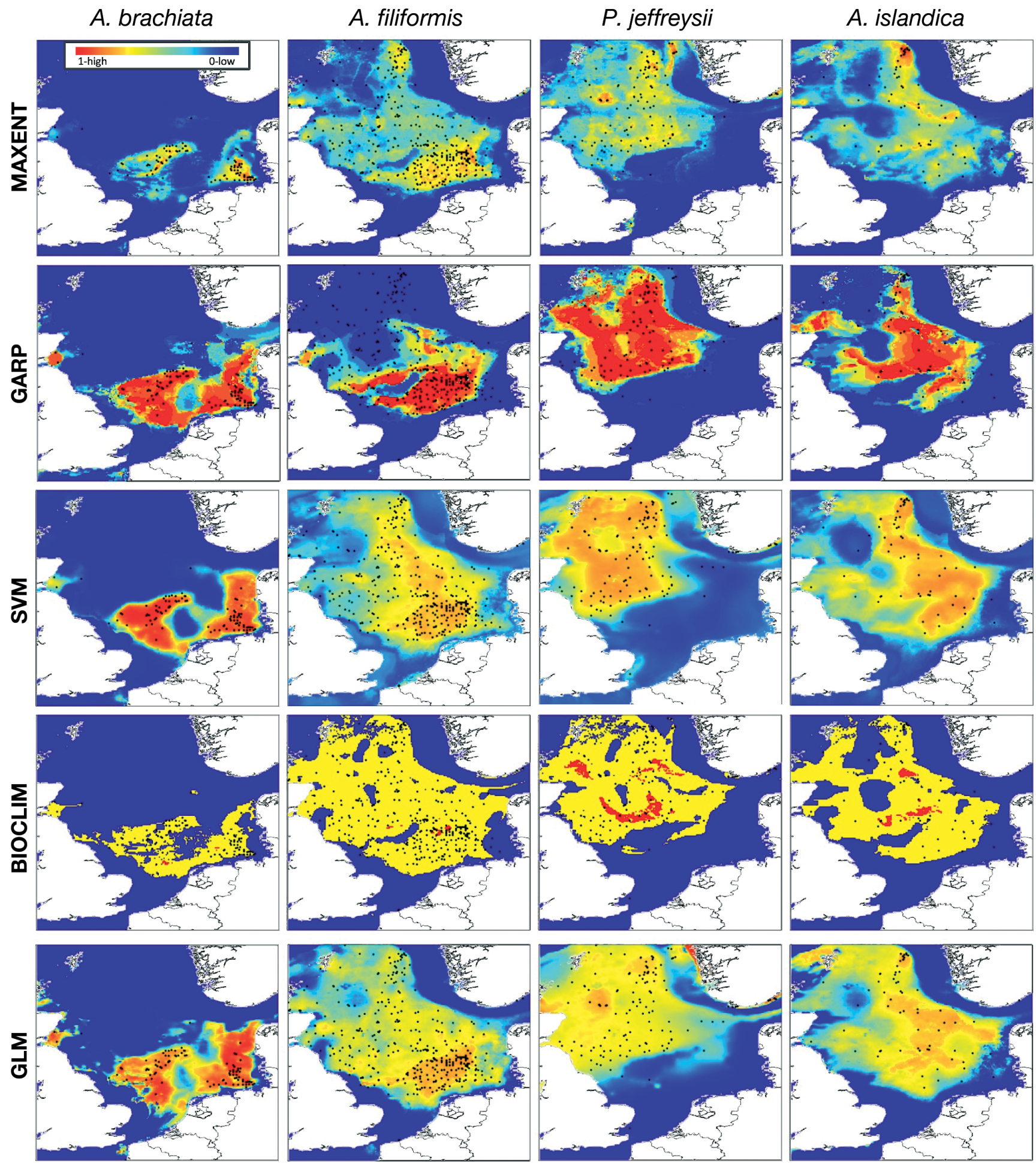

Fig. 2. (this page and continued overleaf). Acrocnida brachiata, Amphiura filiformis, Paramphinome jeffreysii and Arctica islandica. Distribution maps (probability of occurrence) and observed occurrence $(\bullet)$ of 4 selected species derived with the different models (for AUC values see Table 1)

nard \& Quinn 2007, Graham et al. 2008, Elith \& Graham 2009, Giovanelli et al. 2010). For example, Elith et al. (2006) compared 16 modelling approaches based on 226 terrestrial animal and plant species, and found that MAXENT, generalised dissimilarity models (GDM) and boosted regression tress (BRT) 


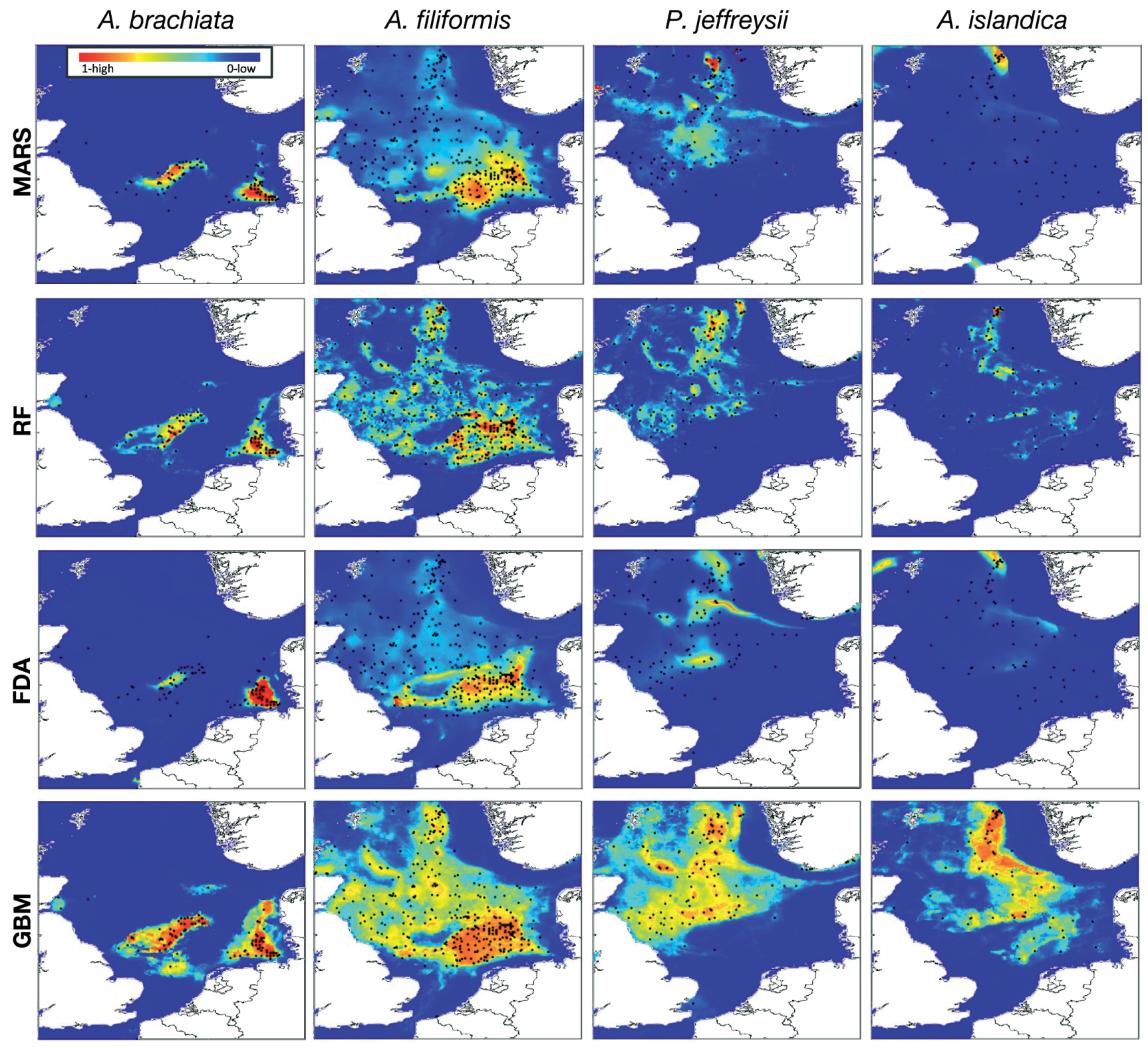

Fig. 2 (continued)

Table 2. Mean percentage of area disagreement (\%) between model predictions

\begin{tabular}{|lccccccc|}
\hline & MAXENT & SVM & GARP & BIOCLIM & GLM & GBM & MARS \\
\hline SVM & 12.2 & - & - & - & - & - & - \\
GARP & 15.4 & 15.1 & - & - & - & - & - \\
BIOCLIM & 28.6 & 28.9 & 25.4 & - & - & - & - \\
GLM & 14.6 & 15.6 & 15.2 & 25.2 & - & - & - \\
GBM & 8.4 & 12.1 & 14.3 & 29.5 & 16.0 & - & - \\
MARS & 14.0 & 14.7 & 17.5 & 31.1 & 17.3 & 12.9 & - \\
RF & 15.4 & 17.3 & 19.8 & 32.5 & 20.2 & 12.5 & - \\
FDA & 12.7 & 14.7 & 17.2 & 30.5 & 16.4 & 12.8 & - \\
\end{tabular}



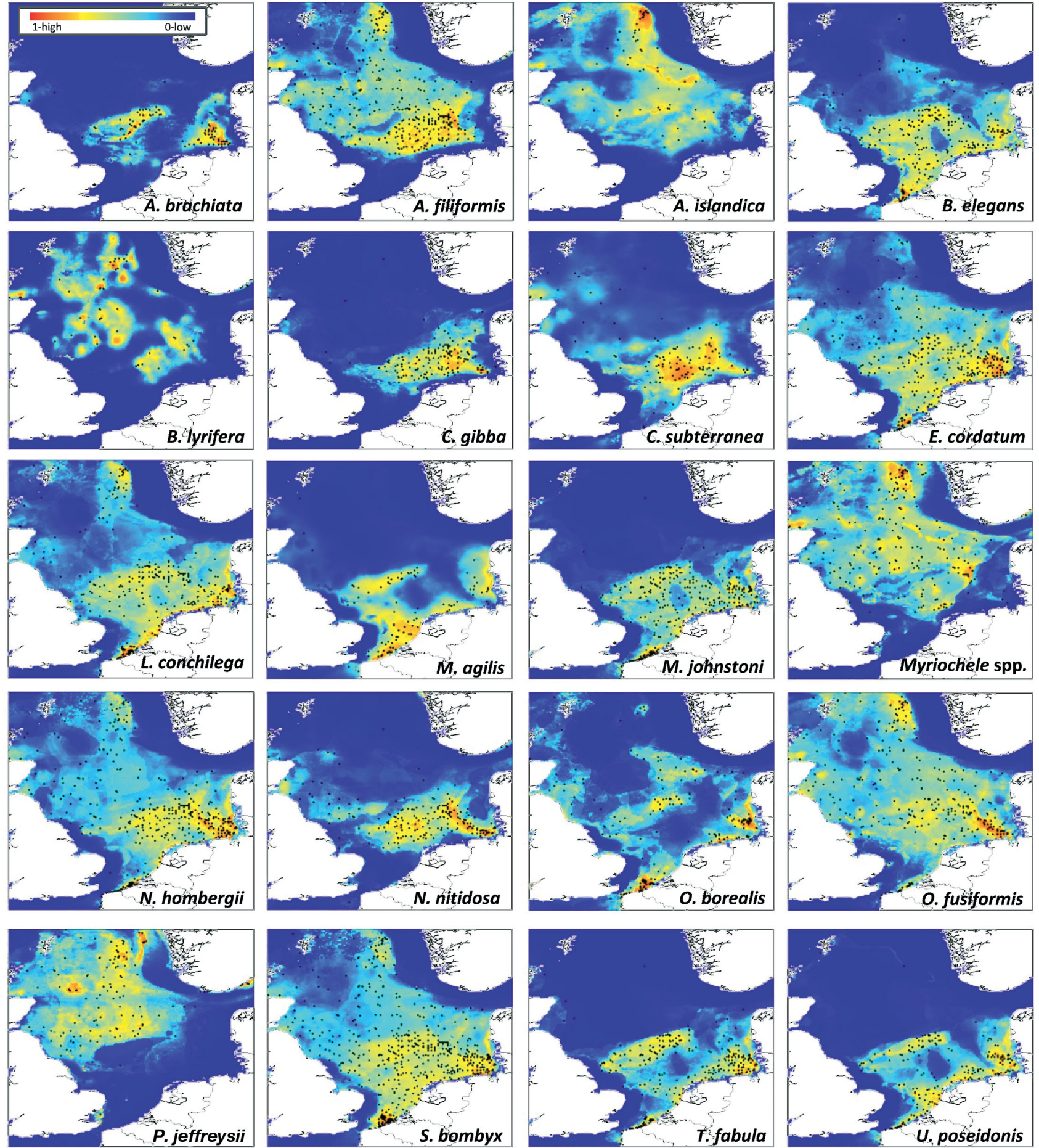

Fig. 3. Distribution maps (probability of occurrence) and observed occurrence $(\bullet$ ) of all species derived with MAXENT (for AUC values and full species names, see Table 1)

performed best, followed by MARS, GLM, generalised additive models (GAM) and GARP. Methods such as BIOCLIM and Domain performed poorly. Our study also found that MAXENT and GBM performed best, based on AUC and $\kappa$ scores. Most of the other modelling algorithms such as SVM, MARS, FDA and RF, as well as GLM and GARP, were largely indistinguishable from each other, but also performed well. In contrast, BIOCLIM performed poorly based on AUC and $\kappa$ values (Fig. 1). Most previous species dis- 

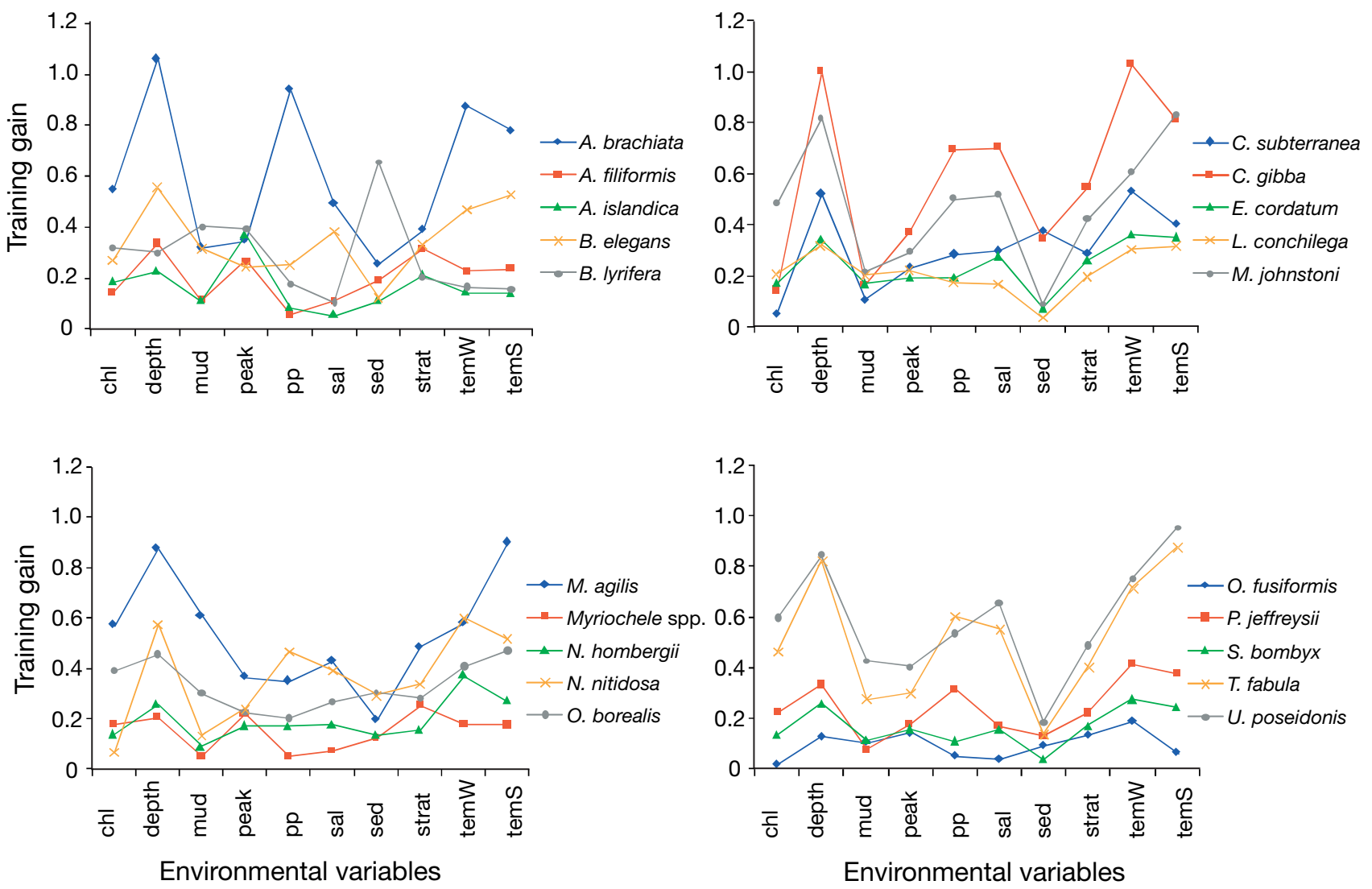

Fig. 4. Results of the jackknife test of variable importance of MAXENT indicating the explanatory power in terms of training gain when only a single environmental variable is included in the MAXENT model. Environmental variables are given as follows: $\mathrm{chl}=$ chlorophyll of the surface water $;$ depth $=$ water depth; mud $=$ mud content of the sediment; peak $=$ peak stress; pp $=$ primary production; sal $=$ bottom water salinity; sed = median grain size; strat $=$ stratification index; temW $=$ bottom water temperature in winter; temS = bottom water temperature in summer

tribution modelling in the marine environment has focused on regression-based models such as GLMs (e.g. Venables \& Dichmont 2004, Willems et al. 2008, Chatfield et al. 2010, Gogina et al. 2010), but our results show that machine-learning and other methods were successful in predicting North Sea benthic species distributions (see also Willems et al. 2008). Nevertheless, visual assessment of the mapped predictions revealed remarkable differences between the methods. Models such as GARP overpredicted habitat suitability for different species, whereas RF, FDA and MARS underpredicted habitat suitability (Fig. 2). Elith \& Graham (2009) showed that GARP could not identify the true relationship between simulated plant species and environmental data, and output maps overpredicted distributions. In contrast, methods such as MAXENT and BRT (similar to GBM) recreated the distribution patterns more precisely (Elith \& Graham 2009). Both methods also generated very similar predictions of potential species distribution across all species in our study (Table 2). How- ever, the choice of modelling method depends on the specific application. Methods which tend to underpredict distribution patterns might be useful for species protection applications (e.g. Marine Protected Areas), whereas overprediction can be more useful for other precautionary management strategies (e.g. to limit the spread of invasive species).

The model evaluation in this study was primarily based on the AUC, since it neither requires a specific threshold nor depends on prevalence (e.g. Cohen's kappa; McPherson et al. 2004). Nevertheless, recent studies on the drawbacks of using the AUC (Austin 2007, Lobo et al. 2008) showed that the influences on the AUC scores of the total extent to which models are carried out are highly problematic (Lobo et al. 2008). Despite differences in performance between models, our results agree with previous studies of terrestrial ecosystems that show higher accuracy for species with a narrow ecological niche compared to species with a broad niche (see Tsoar et al. 2007 and references therein). A possible ecological explana- 

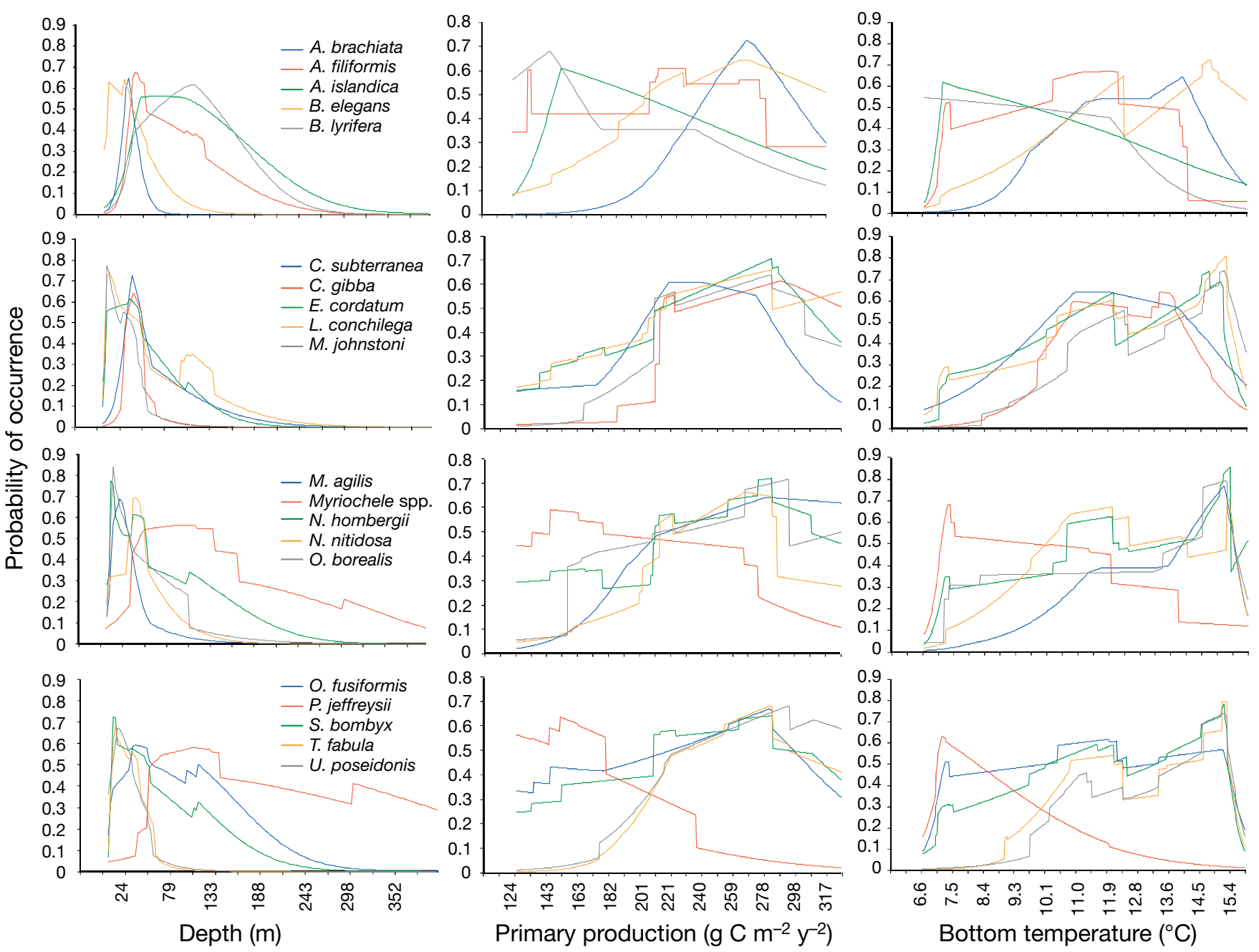

Fig. 5. Response curves of all species for depth, primary production and bottom temperature (summer) derived with MAXENT

tion for this pattern is that the species inhabiting most parts of the area for which the model was trained might not be limited by any of the environmental variables at this spatial scale (Brotons et al. 2004, McPherson \& Jetz 2007). Intraspecific genetic differences may also lead to differences in local adaptations and small-scale population differentiation within the spatial range of the species, which are not accounted for by modelling the potential distribution of the species as an entity (Stockwell \& Peterson 2002, Rissler \& Apodaca 2007). The pattern may just be an artificial function of the spatial extent of the analyses. Lobo et al. (2008) pointed out that different species have distinct ratios between the extent of occurrence and the extent of the area under study, which is smaller for species with a narrow ecological niche (based on the limited spatial extent). The smaller this ratio, the higher the number of (pseudo-)absence points that are more environmentally distant from the presence points, which leads to higher AUC scores (Elith et al. 2006, Jiménez-Valverde et al. 2008, Lobo et al. 2008). Thus, the comparison of model performances for different species within the same spatial extent must be interpreted with caution when applying and evaluating species distribution models. In contrast, the consistent relationship between number of occurrence records and model performance indicated by previous studies (e.g. Stockwell \& Peterson 2002, Kadmon et al. 2003, but see Elith et al. 2006), was not obvious in our study, in that species occurrences ranged from 26 to 568 records.

Although our results indicate that most of the SDM methods generate sufficient predictions of potential distribution for most of the selected benthic species, there were some remarkable differences in performance. Autecological characteristics of the species can significantly affect model accuracy. Species range (see above), mobility and migratory behaviour, 
endemism and even body size can influence predictive models (Pearce et al. 2001, Kadmon et al. 2003, McPherson \& Jetz 2007, Marmion et al. 2009). The mobility and dispersal range might be of specific importance in marine ecosystems, where most species have either mobile adult stages (e.g. epibenthos, fish) or highly mobile early life stages (e.g. pelagic larvae). Furthermore, dispersal barriers are less distinct in marine than in terrestrial systems (Carr et al. 2003). Dispersal of pelagic larvae or secondary dispersal of juvenile invertebrates can facilitate recruitment to suboptimal habitats where species can persist for longer time periods as sink populations (Pulliam 2000). The possible effect of sink populations and dispersal ability have to be considered when applying and interpreting species distribution models (McPherson et al. 2004, Tsoar et al. 2007). In order to account for mobility and dispersal abilities of individual species, some approaches incorporate dispersal into distribution modelling approaches (e.g. by coupling SDM to dispersal simulations; Bahn et al. 2008, Václavík \& Meentemeyer 2009). However, our understanding of dispersal pathways and species interactions is often limited for marine benthic ecosystems and their inclusion into prognostic SDM approaches remain a challenging but important need (Pearson \& Dawson 2003, Elith \& Leathwick 2009, Van der Putten et al. 2010).

Environmental measurements on relevant spatial scales provide the fundamental basis of species distribution modelling. Especially for marine ecosystems, the availability of large-scale environmental data has significantly improved in the last decade, through increased research in habitat mapping and remote sensing techniques, and regular monitoring of the seafloor environment.

To be useful in a distribution modelling context, environmental variables should ideally represent limiting factors, resources or disturbances (natural or anthropogenic) causally linked to the species of interest and its habitat (Guisan \& Zimmermann 2000, Guisan \& Thuiller 2005, Elith \& Leathwick 2009). For our predictors, we chose 10 environmental variables thought to influence benthic habitat and species (e.g. Pearson \& Rosenberg 1987, Heip \& Craeymeersch 1995, Callaway et al. 2002, Wieking \& Kröncke 2005). However, in many cases we used modelled environmental data (e.g. bottom water temperature and salinity, tidal stress, annual primary production), which might have added to uncertainty of the SDM outputs. Nevertheless, variables acting near the sea bottom are particularly influential for benthic ecosystems. Thus, sea surface data, which are often more readily available, may not reflect seafloor conditions sufficiently. The differences in the spatial resolution of the original environmental variables and the interpolation to a standardised grid size needed for the application of the models may also have impacted the predictive output of the SDM (e.g. Guisan \& Zimmermann 2000, Austin \& Van Niel 2011). Environmental variables with a distinct small-scale patchiness (e.g. sediment composition) will be more affected by differences in resolution than variables with less intrinsic variability (e.g. temperature). Thus, the sediment composition variables used in this study might only partly represent the fine-scale resolution necessary for a predictor variable over such a large scale. Indeed, the contributions of single environmental variables to the MAXENT results in our study showed that sediment composition was of minor importance for the distribution predictions of most species, with the exception of the echinoderm Brissopsis lyrifera (Fig. 4). Sediment characteristics have often been found to affect benthic infaunal community patterns (e.g. Rees et al. 1999, Callaway et al. 2002, van Hoey et al. 2004, Schratzberger et al. 2006) and were primarily used to develop a SDM for polychaete distribution in the southern North Sea (Meißner et al. 2008). Besides the methodological problems mentioned above, we assume that the relative importance of the influencing factors may vary with the spatial scale and the autecological characteristics of the species. Thus, on a smaller spatial scale, the distribution of benthic species might be more closely linked to sediment characteristics and small-scale bottom topography, whereas on larger scales, hydrologic and climatic variables might be more important (Reiss et al. 2010). This possible scale dependency should also be considered when transferring models developed for one region to another (e.g. Randin et al. 2006, Elith \& Leathwick 2009).

Bottom temperature and depth influenced distributions of many benthic species in our study. While depth is an indirect proxy for several environmental variables, many studies assume temperature to be an important variable for benthic species and community distributions (e.g. Callaway et al. 2002, Neumann et al. 2009, Reiss et al. 2010). For example, the amphipod Megaluropus agilis and the echinoderm Acrocnida brachiata are sensitive to changes in water temperature in the North Sea (Wieking \& Kröncke 2003), which was also evident in the MAXENT results. Temperature also influenced the distribution of other characteristic species, such as Corbula gibba, Magelona johnstoni, Tellina fabula or Urothoe poseidonis. It is important to recognise that correla- 
tive approaches such as SDMs do not reveal cause-effect relationships between environmental variables and benthic fauna. Surrogate variables, such as water depth, might be especially useful in a correlative approach to predict actual distribution, but cause-effect relationships must be better understood to enable reliable predictions of distribution shifts in changing environments.

One main objective of applying distribution modelling methods to marine benthic species is to predict changes of distribution patterns in response to climate change. Our results demonstrate the utility of the different models for predicting potential distributions of North Sea benthic species and the importance of climatic variables such as bottom temperature. We do not suggest equal applicability of these models for the prediction of future distributions under different climates (Pearson \& Dawson 2003, Hampe 2004, Thuiller 2004, Araújo et al. 2005). The main problem for prognostic species distribution modelling is that processes such as species interactions, habitat change, rapid evolutionary changes, and dispersal range and barriers are not included in most of the modelling approaches. Changes in species interactions (predation, competition, symbiosis) can significantly affect species distributions (e.g. Mouritsen et al. 2005, Traill et al. 2010), which might be further altered by invasions of non-native species facilitated by climate change, resulting in novel combinations of species (Walther et al. 2009). As the modelled species distribution is based on present-day conditions, future changes in species interactions are not considered and this can lead to erroneous model predictions. Although species interactions are expected to be less important on a global or regional scale (e.g. North Sea) than on a local scale, Araújo \& Luoto (2007) have demonstrated effects of species interactions on these macro-scales.

This study focused on predicting the probability of species occurrences, but quantitative predictions (e.g. abundance or biomass) of marine benthic species are also needed in order to understand largescale ecosystem processes. Estimating abundance simply by using the probability of occurrence as a proxy is not possible (at least for the benthic species analysed in this study), because these 2 parameters are not significantly correlated (H. Reiss unpubl. data). Thus, Bayesian and other modelling approaches will be necessary tools in future prediction of quantitative characteristics of species distribution (Pearce \& Boyce 2006, Potts \& Elith 2006, Anadón et al. 2010, Chakraborty et al. 2010). These approaches will be especially valuable for the marine benthic en- vironment, where sampling and observation depend on point data records.

Acknowledgements. We thank the members of the ICES North Sea Benthos Project 2000 and colleagues from the EU Project MAFCONS for providing benthic data. Thanks also to the following colleagues and to the organisations they represent for providing environmental data: T. Pohlmann and A. Moll (Institute of Oceanography, Germany), J. Aldridge and J. Wolf (Proudman Oceanographic Labs, UK), J. Geißler (Brockmann Consult, Germany). Thanks to K. Reiss for helpful comments on an earlier version of the manuscript and to the anonymous referees for their valuable comments. The study is a contribution from the Research Centre on Biodiversity and Climate (BiK-F).

\section{LITERATURE CITED}

Anadón JD, Giménez A, Ballestar R (2010) Linking local ecological knowledge and habitat modelling to predict absolute species abundance on large scales. Biodivers Conserv 19:1443-1454

Araújo MB, Luoto M (2007) The importance of biotic interactions for modelling species distributions under climate change. Glob Ecol Biogeogr 16:743-753

Araújo MB, Pearson RG, Thuiller W, Erhard M (2005) Validation of species-climate impact models under climate change. Glob Change Biol 11:1504-1513

Austin M (2007) Species distribution models and ecological theory: a critical assessment and some possible new approaches. Ecol Model 200:1-19

Austin MP, Van Niel KP (2011) Improving species distribution models for climate change studies: variable selection and scale. J Biogeogr 38:1-8

Backhaus JO (1985) A three-dimensional model for simulation of shelf sea dynamics. Dtsch Hydrogr Z 38:165-187

Bahn V, Krohn WB, O'Connor RJ (2008) Dispersal leads to spatial autocorrelation in species distributions: a simulation model. Ecol Model 213:285-292

Beck JR, Shultz EK (1986) The use of ROC curves in test performance evaluation. Arch Pathol Lab Med 110:13-20

Blott SJ, Pye K (2001) GRADISTAT: a grain size distribution and statistics package for the analysis of unconsolidated sediments. Earth Surf Process Landf 26:1237-1248

Booth GD, Niccolucci MJ, Schuster EG (1994) Identifying proxy sets in multiple linear regression: an aid to better coefficient interpretation. US Dept of Agriculture Forest Service, Ogden, UT

> Brotons L, Thuiller W, Araújo MB, Hirzel AH (2004) Presence-absence versus presence-only modelling methods for predicting bird habitat suitability. Ecography 27: 437-448

Busby JR (1986) A bioclimatic analysis of Nothofagus cunninghami (Hook) Oerst. in southeastern Australia. Aust J Ecol 11:1-7

Callaway R, Alsvag J, de Boois I, Cotter J and others (2002) Diversity and community structure of epibenthic invertebrates and fish in the North Sea. ICES J Mar Sci 59: 1199-1214

Callaway R, Robinson L, Greenstreet S, Reiss H and others (2007) Methodology for the combined sampling of marine groundfish and benthic invertebrate communities. Fisheries Research Services (No 11/07), Aberdeen 
Carr MH, Neigel JE, Estes JA, Andelman S, Warner RR, Largier JL (2003) Comparing marine and terrestrial ecosystems: implications for the design of coastal marine reserves. Ecol Appl 13 (Suppl):90-107

> Chakraborty A, Gelfand AE, Wilson AM, Latimer AM, Silander JA (2010) Modeling large scale species abundance with latent spatial processes. Ann Appl Stat 4:1403-1429

> Chatfield BS, Van Niel KP, Kendrick GA, Harvey ES (2010) Combining environmental gradients to explain and predict the structure of demersal fish distributions. J Biogeogr 37:593-605

> Cohen J (1960) A coefficient of agreement for nominal scales. Educ Psychol Meas 20:37-46

> Davies AM, Aldridge JN (1993) A numerical model study of parameters influencing tidal currents in the Irish Sea. J Geophys Res 98:7049-7068

> Degraer S, Verfaillie E, Willems W, Adriaens E, Vincx M, Van Lancker V (2008) Habitat suitability modelling as a mapping tool for macrobenthic communities: an example from the Belgian part of the North Sea. Cont Shelf Res 28: 369-379

> Drake JM, Randin C, Guisan A (2006) Modelling ecological niches with support vector machines. J Appl Ecol 43: 424-432

- Elith J, Graham CH (2009) Do they? How do they? WHY do they differ? On finding reasons for differing performances of species distribution models. Ecography 32:66-77

> Elith J, Leathwick JR (2009) Species distribution models: Ecological explanation and prediction across space and time. Annu Rev Ecol Evol Syst 40:677-697

Elith J, Graham CH, Anderson RP, Dudík M and others (2006) Novel methods improve prediction of species' distributions from occurrence data. Ecography 29:129-151

Elith J, Leathwick JR, Hastie T (2008) A working guide to boosted regression trees. J Anim Ecol 77:802-813

- Elith J, Phillips SJ, Hastie T, Dudík M, Chee YE, Yates CJ (2011) A statistical explanation of MaxEnt for ecologists. Divers Distrib 17:43-57

Ellis J, Ysebaert T, Hume T, Norkko A and others (2006) Predicting macrofaunal species distributions in estuarine gradients using logistic regression and classification systems. Mar Ecol Prog Ser 316:69-83

ESA (European Space Agency) (2006) MERIS product handbook. European Space Agency

Fielding AH, Bell JF (1997) A review of methods for the assessment of prediction errors in conservation presence/ absence models. Environ Conserv 24:38-49

Friedman JH (1991) Multivariate adaptive regression splines. Ann Stat 19:1-67

GEBCO (2003) General Bathymetric Charts of the Oceans. www.bodc.ac.uk/products/gebco.html (accessed Sep 2009)

> Giovanelli JGR, de Siqueira MF, Haddad CFB, Alexandrino $\mathrm{J}$ (2010) Modeling a spatially restricted distribution in the Neotropics: How the size of calibration area affects the performance of five presence-only methods. Ecol Model 221:215-224

Glockzin M, Gogina M, Zettler ML (2009) Beyond salty reins-modeling benthic species' spatial response to their physical environment in the Pomeranian Bay (southern Baltic Sea). Balt Coast Zone 13:79-95

Gogina M, Zettler ML (2010) Diversity and distribution of benthic macrofauna in the Baltic Sea: data inventory and its use for species distribution modelling and prediction. J Sea Res 64:313-321
Gogina M, Glockzin M, Zettler ML (2010) Distribution of benthic macrofaunal communities in the western Baltic Sea with regard to near-bottom environmental parameters. 2. Modelling and prediction. J Mar Syst 80:57-70

Graham CH, Elith J, Hijmans RJ, Guisan A, Peterson AT, Loiselle BA (2008) The influence of spatial errors in species occurrence data used in distribution models. J Appl Ecol 45:239-247

> Guisan A, Thuiller W (2005) Predicting species distribution: offering more than simple habitat models. Ecol Lett 8: 993-1009

Guisan A, Zimmermann NE (2000) Predictive habitat distribution models in ecology. Ecol Model 135:147-186

Guo QH, Kelly M, Graham CH (2005) Support vector machines for predicting distribution of sudden oak death in California. Ecol Model 182:75-90

Hampe A (2004) Bioclimate envelope models: what they detect and what they hide. Glob Ecol Biogeogr 13: 469-471

> Heikkinen RK, Luoto M, Araujo MB, Virkkala R, Thuiller W, Sykes MT (2006) Methods and uncertainties in bioclimatic envelope modelling under climate change. Prog Phys Geogr 30:751-777

- Heip C, Craeymeersch JA (1995) Benthic community structures in the North Sea. Helgol Meeresunters 49:313-328

Hosmer DW, Lemeshow S (2000) Applied logistic regression. Wiley Interscience, New York

> Jiménez-Valverde A, Lobo JM, Hortal J (2008) Not as good as they seem: the importance of concepts in species distribution modelling. Divers Distrib 14:885-890

Kadmon R, Farber O, Danin A (2003) A systematic analysis of factors affecting the performance of climatic envelope models. Ecol Appl 13:853-867

Kharouba HM, Algar AC, Kerr JT (2009) Historically calibrated predictions of butterfly species' range shift using global change as a pseudo-experiment. Ecology 90: 2213-2222

> Kröncke I, Reiss H, Eggleton JD, Bergman MJN and others (2011) Changes in North Sea macrofauna communities and species distribution between 1986 and 2000. Estuar Coast Shelf Sci 94:1-15

> Landis JR, Koch GG (1977) Measurement of observed agreement for categorical data. Biometrics 33:159-174

Leathwick J, Moilanen A, Francis M, Elith J and others (2008) Novel methods for the design and evaluation of marine protected areas in offshore waters. Conserv Lett 1:91-102

Lenoir S, Beaugrand G, Lecuyer É (2011) Modelled spatial distribution of marine fish and projected modifications in the North Atlantic Ocean. Glob Change Biol 17:115-129

Lobo JM, Jiménez-Valverde A, Real R (2008) AUC: a misleading measure of the performance of predictive distribution models. Glob Ecol Biogeogr 17:145-151

Marmion M, Luoto M, Heikkinen RK, Thuiller W (2009) The performance of state-of-the-art modelling techniques depends on geographical distribution of species. Ecol Model 220:3512-3520

Maxwell DL, Stelzenmuller V, Eastwood PD, Rogers SI (2009) Modelling the spatial distribution of plaice (Pleuronectes platessa), sole (Solea solea) and thornback ray (Raja clavata) in UK waters for marine management and planning. J Sea Res 61:258-267

McPherson JM, Jetz W (2007) Effects of species' ecology on the accuracy of distribution models. Ecography 30: 135-151 
McPherson JM, Jetz W, Rogers DJ (2004) The effects of species' range sizes on the accuracy of distribution models: ecological phenomenon or statistical artefact? J Appl Ecol 41:811-823

Meißner K, Darr A, Rachor E (2008) Development of habitat models for Nephtys species (Polychaeta: Nephtyidae) in the German Bight (North Sea). J Sea Res 60:276-291

> Meynard CN, Quinn JF (2007) Predicting species distributions: a critical comparison of the most common statistical models using artificial species. J Biogeogr 34:1455-1469

Moll A (1998) Regional distribution of primary production in the North Sea simulated by a three-dimensional model. J Mar Syst 16:151-170

Moll A (2000) Assessment of three-dimensional physical-biological ECOHAM1 simulations by quantified validation for the North Sea with ICES and ERSEM data. ICES J Mar Sci 57:1060-1068

- Moore CH, Harvey ES, Van Niel K (2010) The application of predicted habitat models to investigate the spatial ecology of demersal fish assemblages. Mar Biol 157: $2717-2729$

> Mouritsen KN, Tompkins DM, Poulin R (2005) Climate warming may cause a parasite-induced collapse in coastal amphipod populations. Oecologia 146:476-483

> Muñoz MES, De Giovanni R, Siqueira MF, Sutton T and others (2011) openModeller: a generic approach to species' potential distribution modelling. GeoInformatica 15: 111-135

- Neumann H, Reiss H, Rakers S, Ehrich S, Kröncke I (2009) Temporal variability in southern North Sea epifauna communities after the cold winter of 1995/1996. ICES J Mar Sci 66:2233-2243

Nix HA (1986) A biogeographic analysis of Australian elapid snakes. In: Longmore R (ed) Atlas of elapid snakes of Australia, Australian flora and fauna Series No. 7. Australian Government Publishing Service, Canberra, p 4-15

Osuna P, Wolf J (2005) Results from a one-year run of a wave model for the UK continental shelf. Proudman Oceanographic Laboratory, Liverpool

Pearce JL, Boyce MS (2006) Modelling distribution and abundance with presence-only data. J Appl Ecol 43: 405-412

> Pearce J, Ferrier S, Scotts D (2001) An evaluation of the predictive performance of distributional models for flora and fauna in north-east New South Wales. J Environ Manage 62:171-184

Pearson RG, Dawson TP (2003) Predicting the impacts of climate change on the distribution of species: are bioclimate envelope models useful? Glob Ecol Biogeogr 12: 361-371

Pearson TH, Rosenberg R (1987) Feast and famine: structuring factors in marine benthic communities. In: Gee JHR, Giller PS (eds) The 27th Symposium of The British Ecological Society, Aberystwyth 1986. Blackwell Scientific, Oxford, p 373-395

Peterson AT, Papes M, Eaton M (2007) Transferability and model evaluation in ecological niche modeling: a comparison of GARP and Maxent. Ecography 30:550-560

Phillips S (2005) A brief tutorial on Maxent. AT\&T Research. www.cs.princeton.edu/ schapire/maxent/tutorial/tutorial. doc (accessed Apr 2010)

Phillips SJ, Anderson RP, Schapire RE (2006) Maximum entropy modeling of species geographic distributions. Ecol Model 190:231-259

Pingree RD, Griffiths DK (1978) Tidal fronts on shelf seas around British Isles. J Geophys Res 83:4615-4622

> Pohlmann T (1996) Predicting the thermocline in a circulation model of the North Sea. 1. Model description, calibration and verification. Cont Shelf Res 16:131-146

> Pompe S, Hanspach J, Badeck F, Klotz S, Thuiller W, Kühn I (2008) Climate and land use change impacts on plant distributions in Germany. Biol Lett 4:564-567

> Potts JM, Elith J (2006) Comparing species abundance models. Ecol Model 199:153-163

> Prasad AM, Iverson LR, Liaw A (2006) Newer classification and regression tree techniques: bagging and random forests for ecological prediction. Ecosystems (NY) 9: 181-199

Pulliam HR (2000) On the relationship between niche and distribution. Ecol Lett 3:349-361

R Development Core Team (2009) R: A language and environment for statistical computing. R Foundation for Statistical Computing, Vienna

Randin CF, Dirnböck T, Dullinger S, Zimmermann NE, Zappa M, Guisan A (2006) Are niche-based species distribution models transferable in space? J Biogeogr 33: 1689-1703

Rees HL, Pendle MA, Waldock R, Limpenny DS, Boyd SE (1999) A comparison of benthic biodiversity in the North Sea, English Channel, and Celtic Seas. ICES J Mar Sci 56:228-246

Rees HL, Eggleton JD, Rachor E, Vanden Berghe E (2007) Structure and dynamics of the North Sea benthos, Vol 288. ICES, Copenhagen

> Reiss H, Degraer S, Duineveld GCA, Kröncke I and others (2010) Spatial patterns of infauna, epifauna and demersal fish communities in the North Sea. ICES J Mar Sci 67: 278-293

Ridgeway G (2007) Generalized boosted models: a guide to the gbm package. http://cran.r-project.org/web/packages/ gbm/vignettes/gbm.pdf (accessed Feb 2011)

Rissler LJ, Apodaca JJ (2007) Adding more ecology into species delimitation: ecological niche models and phylogeography help define cryptic species in the black salamander (Aneides flavipunctatus). Syst Biol 56:924-942

> Robinson LM, Elith J, Hobday AJ, Pearson RG, Kendall BE, Possingham HP, Richardson AJ (2011) Pushing the limits in marine species distribution modelling: lessons from the land present challenges and opportunities. Glob Ecol Biogeogr 20:789-802

Schratzberger M, Warr K, Rogers SI (2006) Patterns of nematode populations in the southwestern North Sea and their link to other components of the benthic fauna. J Sea Res 55:113-127

Schröder B (2006) ROC plotting and AUC calculation transferability test. http://brandenburg.geoecology.uni-potsdam. de/users/schroeder/download.html (accessed Apr 2010)

> Skogen MD, Moll A (2000) Interannual variability of the North Sea primary production: comparison from two model studies. Cont Shelf Res 20:129-151

Skogen MD, Moll A (2005) Importance of ocean circulation in ecological modeling: an example from the North Sea. J Mar Syst 57:289-300

Stockwell D, Peters D (1999) The GARP modelling system: problems and solutions to automated spatial prediction. Int J Geogr Inf Sci 13:143-158

Stockwell DRB, Peterson AT (2002) Effects of sample size on accuracy of species distribution models. Ecol Model 148: $1-13$

> Thrush SF, Hewitt JE, Norkko A, Nicholls PE, Funnell GA, 
Ellis JI (2003) Habitat change in estuaries: predicting broad-scale responses of intertidal macrofauna to sediment mud content. Mar Ecol Prog Ser 263:101-112

Thuiller W (2003) BIOMOD - optimizing predictions of species distributions and projecting potential future shifts under global change. Glob Change Biol 9:1353-1362

Thuiller W (2004) Patterns and uncertainties of species' range shifts under climate change. Glob Change Biol 10: 2020-2027

Thuiller W, Lafourcade B, Engler R, Araujo MB (2009) BIOMOD-a platform for ensemble forecasting of species distributions. Ecography 32:369-373

Traill LW, Lim MLM, Sodhi NS, Bradshaw CJA (2010) Mechanisms driving change: altered species interactions and ecosystem function through global warming. J Anim Ecol 79:937-947

Tsoar A, Allouche O, Steinitz O, Rotem D, Kadmon R (2007) A comparative evaluation of presence-only methods for modelling species distribution. Divers Distrib 13:397-405

> Václavík T, Meentemeyer RK (2009) Invasive species distribution modeling (iSDM): Are absence data and dispersal constraints needed to predict actual distributions? Ecol Model 220:3248-3258

Van der Putten WH, Macel M, Visser ME (2010) Predicting species distribution and abundance responses to climate change: why it is essential to include biotic interactions

Editorial responsibility: Paul Snelgrove, St. John's, Newfoundland, Canada across trophic levels. Philos Trans R Soc Lond B Biol Sci 365:2025-2034

van Hoey G, Degrear S, Vincx M (2004) Macrobenthic community structure of soft-bottom sediments at the Belgian Continental Shelf. Estuar Coast Shelf Sci 59:599-613

Venables WN, Dichmont CM (2004) GLMs, GAMs and GLMMs: an overview of theory for applications in fisheries research. Fish Res 70:319-337

> Walther GR, Roques A, Hulme PE, Sykes MT and others (2009) Alien species in a warmer world: risks and opportunities. Trends Ecol Evol 24:686-693

Wieking G, Kröncke I (2003) Macrofauna communities of the Dogger Bank (central North Sea) in the late 1990s: spatial distribution, species composition and trophic structure. Helgol Mar Res 57:34-46

Wieking G, Kröncke I (2005) Is benthic trophic structure affected by quality of food? The Dogger Bank example. Mar Biol 146:387-400

Willems W, Goethals P, Van den Eynde D, Van Hoey G and others (2008) Where is the worm? Predictive modelling of the habitat preferences of the tube-building polychaete Lanice conchilega. Ecol Model 212:74-79

> Ysebaert T, Meire P, Herman PMJ, Verbeek H (2002) Macrobenthic species response surfaces along estuarine gradients: prediction by logistic regression. Mar Ecol Prog Ser 225:79-95

Submitted: March 16, 2011; Accepted: September 7, 2011 Proofs received from author(s): November 14, 2011 